\title{
Context memory formation requires activity- dependent protein degradation in the hippocampus
}

\author{
Patrick K. Cullen, Nicole C. Ferrara, Shane E. Pullins, and Fred J. Helmstetter \\ Department of Psychology, University of Wisconsin-Milwaukee, Milwaukee, Wisconsin 53201, USA
}

\begin{abstract}
Numerous studies have indicated that the consolidation of contextual fear memories supported by an aversive outcome like footshock requires de novo protein synthesis as well as protein degradation mediated by the ubiquitin-proteasome system (UPS). Context memory formed in the absence of an aversive stimulus by simple exposure to a novel environment requires de novo protein synthesis in both the dorsal (dHPC) and ventral (vHPC) hippocampus. However, the role of UPS-mediated protein degradation in the consolidation of context memory in the absence of a strong aversive stimulus has not been investigated. In the present study, we used the context preexposure facilitation effect (CPFE) procedure, which allows for the dissociation of context learning from context-shock learning, to investigate the role of activity-dependent protein degradation in the dHPC and vHPC during the formation of a context memory. We report that blocking protein degradation with the proteasome inhibitor clasto-lactacystin $\beta$-lactone ( $\beta \mathrm{Lac}$ ) or blocking protein synthesis with anisomycin (ANI) immediately after context preexposure significantly impaired context memory formation. Additionally, we examined $20 \mathrm{~S}$ proteasome activity at different time points following context exposure and saw that the activity of proteasomes in the dHPC increases immediately after stimulus exposure while the vHPC exhibits a biphasic pattern of proteolytic activity. Taken together, these data suggest that the requirement of increased proteolysis during memory consolidation is not driven by processes triggered by the strong aversive outcome (i.e., shock) normally used to support fear conditioning.
\end{abstract}

During contextual fear conditioning, which involves pairing a context (conditional stimulus, CS) and footshock (unconditional stimulus, UCS), two independent processes are thought to occur: (1) Upon exposure to a novel context, the animal will encode cues from the environment and form a unitary representation of the context; and then (2) the animal will associate that representation with the aversive UCS when it is delivered (Fanselow 1990; Westbrook et al. 1994; Rudy and O'Reilly 1999; Rudy and MatusAmat 2005). Most studies using traditional context fear conditioning procedures cannot dissociate these two processes as learning about the context and the context-shock association occurs almost simultaneously. However, the context preexposure facilitation effect (CPFE) procedure allows for the separation of context learning from the context-shock learning (Fanselow 1990; Huff and Rudy 2004; Rudy 2005; Rudy and Matus-Amat 2005). When animals are placed into a novel context and "immediately" receive a footshock, they show relatively poor contextual fear learning. Allowing animals to explore the novel context during a preexposure session $24 \mathrm{~h}$ prior to training, however, can ameliorate this immediate shock deficit and support normal performance (Fanselow 1990). Preexposure to the training context may allow the animal to form a conjunctive representation of the context that is retrieved and paired with the UCS during the immediate shock training session (Fanselow 1990; Barrientos et al. 2002; Huff and Rudy 2004; Rudy and Matus-Amat 2005). Furthermore, several studies have demonstrated that the acquisition and consolidation of context memory during the preexposure period requires activity in the hippocampus (Barrientos et al. 2002; Huff and Rudy 2004; Rudy and Matus-Amat 2005). While this procedure has been useful in elucidating the role of the hippocampus in context learning, relatively few studies have investigated molecular mechanisms involved in the formation of a context memory in the absence of aversive

\section{Corresponding author: fjh@uwm.edu}

Article is online at http://www.learnmem.org/cgi/doi/10.1101//m.045443.117.
UCS. One previous study provided evidence that de novo protein synthesis is required in the CA1 region of the dorsal hippocampus (dHPC) following context preexposure to form a representation of the context (Barrientos et al. 2002). Additionally, inhibition of protein translation in the ventral hippocampus (vHPC) following context preexposure impairs context memory in the CPFE (Rudy and Matus-Amat 2005). These studies provide strong evidence that de novo protein synthesis within both the dHPC and vHPC is required for consolidation of the context representation following preexposure, but other mechanisms of synaptic plasticity involved in context learning in the absence of an aversive stimulus have not been well characterized. For example, it is currently unknown whether activity-dependent protein degradation is required within the hippocampus during consolidation of the nonaversive context memory.

It is generally accepted that the acquisition and storage of context fear learning requires gene activation, transcription of mRNA, and translation of new proteins (Flexner et al. 1963; Montarolo et al. 1986; Freeman et al. 1995; Guzowski and McGaugh 1997; Bailey et al. 1999; Kida et al. 2002; Yeh et al. 2004; Alberini 2009; Kinney et al. 2009). This process of gene expression and de novo protein synthesis has been proposed as the necessary step for converting a new labile memory into a stable long-term memory. In addition to de novo protein synthesis, activity-dependent protein degradation, mediated by the ubiquitin-proteasome system (UPS), plays a critical role in the formation and retrieval of stable longterm memories (Lee et al. 2008; Jarome et al. 2011; Jarome and Helmstetter 2013; Reis et al. 2013). In the UPS, proteins are tagged for degradation through the covalent attachment of polyubiquitin

(C) 2017 Cullen et al. This article is distributed exclusively by Cold Spring Harbor Laboratory Press for the first 12 months after the full-issue publication date (see http://learnmem.cshlp.org/site/misc/terms.xhtml). After 12 months, it is available under a Creative Commons License (AttributionNonCommercial 4.0 International), as described at http://creativecommons. org/licenses/by-nc/4.0/. 
Hippocampal protein degradation and consolidation

chains (Hegde 2010). Following ubiquitination, the protein is targeted by the $26 \mathrm{~S}$ proteasome and subsequently degraded. The $26 \mathrm{~S}$ proteasome complex consists of a $20 \mathrm{~S}$ catalytic core and two $19 \mathrm{~S}$ regulatory particles. The $20 \mathrm{~S}$ core of the proteasome, which carries out three major types of proteolytic activity (trypsin-like, chymotrypsin-like, and peptidylglutamyl peptidase activity), is regulated by the $19 \mathrm{~S}$ regulatory particles consisting of six Rpt subunits (Kish-Trier and Hill 2013). Increased phosphorylation of the Rpt6 subunit at Serine120 is associated with increased proteolytic activity in vivo (Jarome et al. 2013) and has been identified as a primary regulator of activity-dependent proteolytic activity in neurons. UPS-mediated protein degradation is a potential mechanism by which synapses become labile during training or memory retrieval, and may actually underlie the well-known requirement for de novo protein synthesis to stabilize the synapses for memory storage (Lee et al. 2008; Jarome and Helmstetter 2013). Degradation is required within the hippocampus for the consolidation of contextual fear conditioning and inhibitory avoidance (LopezSalon et al. 2001). Artinian et al. (2008) reported that intrahippocampal infusions of the $20 \mathrm{~S}$ proteasome inhibitor, Lactacystin, impaired memory for the location of a platform in a modified version of the Morris water maze. More recently, Figueiredo et al. (2015) blocked hippocampal protein degradation following object recognition training, which impaired object recognition memory when tested $24 \mathrm{~h}$ later. These studies suggest that along with protein synthesis, activity-dependent protein degradation is required for consolidation of spatial memory. However, activity of the UPS in the encoding and consolidation of a context memory, in the absence of an aversive UCS, has not been characterized.

Here, we investigated the role of hippocampal UPS-mediated proteolysis in the consolidation of a context memory. First, using the CPFE procedure, we determined the role of activity-dependent protein degradation in the dHPC and vHPC by inhibiting proteolytic activity following context preexposure. We then investigated the time course of increases in activity-dependent protein degradation triggered by context exposure in both the dHPC and vHPC. Previous work suggests a functional distinction between the dorsal and ventral portions of the hippocampus as number of studies have provided evidence suggesting that the dHPC is primarily responsible for processing spatial and contextual learning, whereas the vHPC plays a greater role in fear and anxiety processing (for a review, see Fanselow and Dong 2010). However, Rudy and Matus-Amat (2005) reported that activity of the vHPC is required for context memory formation in the absence of the UCS. We sought to compare potential increases in proteolytic activity to (1) characterize hippocampal proteolytic activity following context exposure and (2) determine whether the dHPC and vHPC undergo similar patterns of synaptic destabilization during the consolidation period. To achieve this, we measured phosphorylation of Rpt6 and changes in the three major types of $20 \mathrm{~S}$ proteolytic activity at various poststimulus time points. Together, our results provide evidence that along with de novo protein synthesis, activitydependent protein degradation is critical in both the dorsal and ventral hippocampus for the consolidation of a purely contextual memory. Further, we demonstrate that the dHPC undergoes immediate procontext. $\left.{ }^{* *}\right) P<0.01$. tein degradation while the vHPC exhibits a biphasic pattern of proteolytic activity following context exposure, suggesting a functional distinction between the dHPC and vHPC.

\section{Results}

\section{Protein synthesis and degradation in the $\mathrm{dHPC}$ are} required for the formation of a context representation Figure 1B shows a diagram of the targeted location of the guide cannulae aimed at the CA1 region of the $\mathrm{dHPC}$ and a representative example of a cannulae placement. Subjects were only used for data analysis if the tip of the cannulae was located slightly above or within, but not below, the CA1 region of the dHPC.

To investigate the role of activity-dependent protein degradation within the dHPC during consolidation of a context representation, we used the preexposure facilitation effect coupled with infusion of the $20 \mathrm{~S}$ proteasome inhibitor $\beta \mathrm{Lac}$ into the CA1 region of the dHPC immediately following context exposure. Separate groups received ANI injections for comparison. The next day, the rats were administered immediate shock in the training context and then tested for memory retention $24 \mathrm{~h}$ later. We predicted that blocking proteasome activity within the dHPC following context exposure would disrupt the consolidation of the context representation as indicated by poor context fear conditioning at test.

The effect of blocking protein degradation ( $\beta \mathrm{Lac}$ ) or protein synthesis (ANI) in the dHPC is shown in Figure 1C. A 2 (context) $\times$ 3 (drug) factorial ANOVA was conducted on freezing scores and yielded a statistically significant Context $\times$ Drug interaction $\left(F_{(2,42)}=10.76, P<0.001\right)$. Vehicle infused animals that were exposed to the control context exhibit poor conditioned freezing when tested for fear in the training context compared to vehicle infused animals that received preexposure to the training context $(P$ $<0.01)$. This difference illustrates the context preexposure facilitation effect. Animals infused with ANI immediately following preexposure to the training context exhibited significantly lower freezing scores compared to vehicle animals $(P<0.01)$. Animals infused with $\beta$ Lac immediately following preexposure to the training
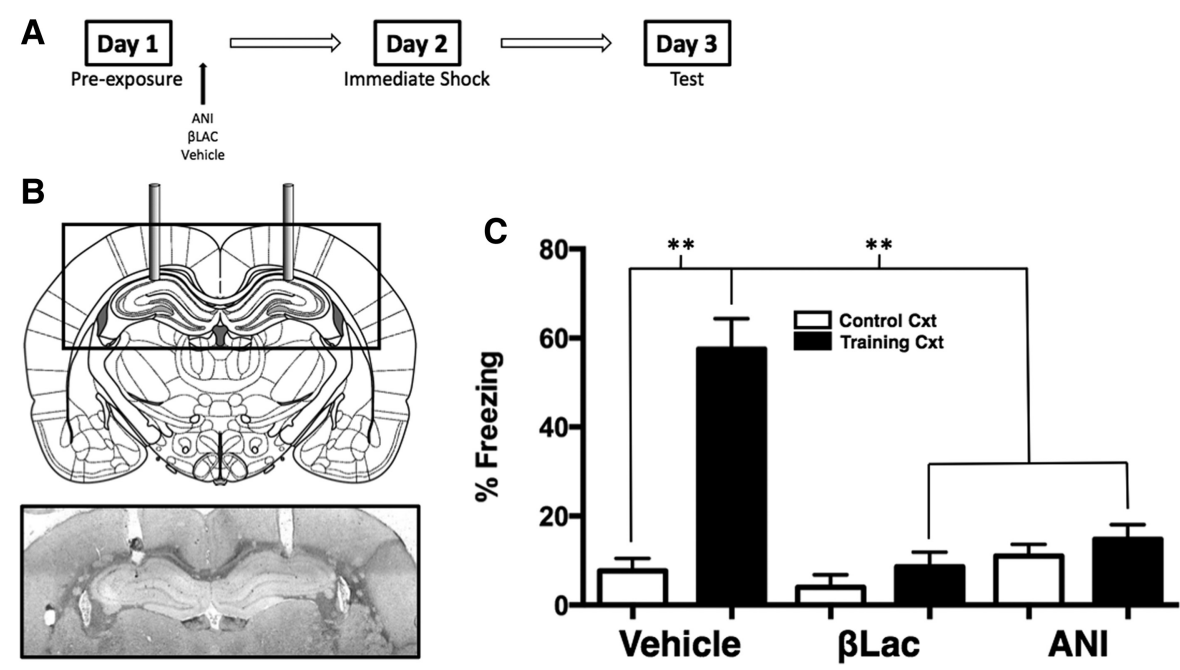

Figure 1. USP-mediated protein degradation and de novo protein synthesis in the dHPC are required for the consolidation of a context representation. $(A)$ Experimental timeline. $(B)$ The diagram shows cannula placement in the CA1 region of the dHPC. The micrograph shows an example placement of dHPC cannula. (C) Average freezing levels during the 5-min context test. Vehicle animals froze significantly more if they were preexposed to the Training context compared to animals that were preexposed to the Control context. Rats preexposed to the Training context and infused with ANI or $\beta$ Lac exhibited impaired freezing during the context test compared to Vehicle animals preexposed to the Training 
context similarly exhibited lower freezing scores than vehicle animals exposed to the training context $(P<0.01)$. These data suggest that activity-dependent protein degradation is required in the CA1 region of the dorsal hippocampus for the consolidation of a context representation in the absence of the UCS. Importantly, these data provide support that simple exposure to a conditioning chamber, in the absence of any aversive stimuli, initiates cellular processes associated with synaptic plasticity (i.e., protein degradation and synthesis) within the dHPC and that these plasticity mechanisms are required for the successful consolidation of a context representation.

\section{Protein synthesis and degradation in the vHPC are required for the formation of a context representation}

Here we used the preexposure facilitation effect coupled with infusion of ANI or $\beta$ Lac directly into the vHPC to investigate the role of activity-dependent protein degradation within the vHPC during consolidation of a context representation. Figure 2B shows a diagram of the targeted location of the guide cannulae aimed at the CA1 region of the vHPC and a representative example of a cannulae placement. The effect of blocking protein degradation and protein synthesis in the vHPC is shown in Figure 2C. A 2 (context) $\times 3$ (drug) factorial ANOVA was conducted on freezing scores and yielded a significant Context by Drug interaction $\left(F_{(2,57)}=12.16\right.$, $P<0.001)$. Vehicle infused animals that were exposed to the control context exhibit poor conditioned freezing when tested for fear in the training context compared to vehicle infused animals that were preexposed to the training context $(P<0.01)$. Animals infused with ANI immediately following preexposure to the training context exhibited statistically significantly lower freezing scores compared to vehicle animals $(P<0.01)$. Infusion of $\beta$ Lac into the vHPC immediately following preexposure to the training context resulted in statistically significantly lower freezing levels than vehicle animals exposed to the training context $(P<0.01)$. These data suggest that both de novo protein synthesis and activitydependent protein degradation are required in the CA1 region of the ventral hippocampus for the consolidation of a context representation. Again, these data demonstrate that exposure to a con-
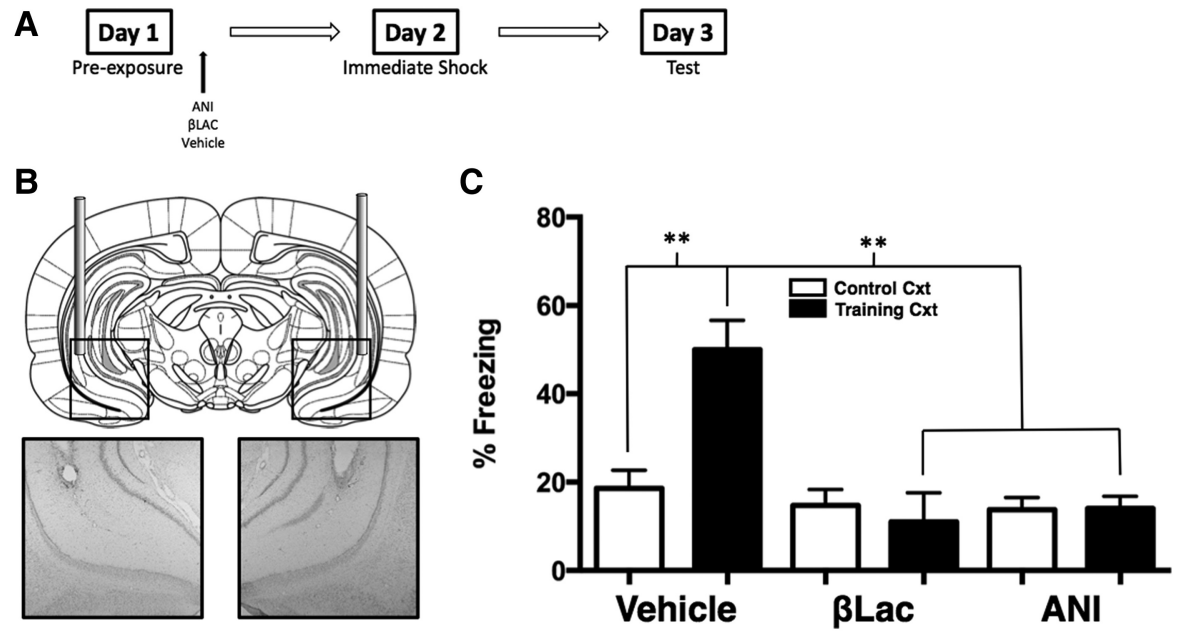

Figure 2. USP-mediated protein degradation and de novo protein synthesis in the vHPC are required for the consolidation of a context representation. $(A)$ Experimental timeline. $(B)$ The diagram shows cannula placement in the vHPC. The micrographs show example placements of vHPC cannula. (C) Average freezing levels during the 5-min context test. Vehicle animals froze significantly more if they were preexposed to the Training context compared to animals that were preexposed to the Control context. Rats preexposed to the Training context and infused with ANI or $\beta$ Lac exhibited impaired freezing during the context test compared to Vehicle animals preexposed to the Training context. $\left({ }^{* *}\right) P<0.01$. text alone is sufficient in engaging mechanism of synaptic plasticity in the hippocampus (both the dHPC and vHPC) and provide the first evidence that hippocampal proteolytic activity, in addition to protein synthesis, is required for the formation of a nonaversive context representation.

\section{The dHPC and vHPC undergo temporally distinct patterns of increased proteolytic activity following context exposure}

We next wanted to assess the time course of proteolytic activity following a context exposure and determine whether the dHPC and vHPC undergo similar patterns of proteolytic activity. To assess changes in proteasome catalytic activity, we exposed rats to the training context and sacrificed animals at various time points to measure proteasome activity in synaptic fractions using both Western blots and an in vitro proteasome activity assay (Jarome et al. 2016). First, we measured phosphorylation of the proteasome regulatory subunit Rpt6 (pRpt6 S-120) in the dHPC and vHPC (Fig. $3 \mathrm{~A})$. Phosphorylated Rpt6 activity marginally increased in the dHPC immediately following context exposure and remained elevated for $30 \mathrm{~min}$ until returning to baseline by $60 \mathrm{~min}$ (Fig. 3B). While there was a significant main effect for time following context exposure $\left(F_{(5,42)}=3.64, P<0.01\right)$, the observed increases at 0 and $30 \mathrm{~min}$ were not statistically significant. Additionally, we found a statistically significant main effect for time after context exposure for pRpt6 in the vHPC $\left(F_{(5,45)}=4.97, P<0.01\right)$ (Fig. 3C). Ventral hippocampal pRpt6 activity increased immediately following context exposure $(P<0.01)$ and returned back to baseline activity levels by $30 \mathrm{~min}$. These data indicate that phosphorylation of the Rpt6 subunit occurs immediately following context exposure in both the dHPC and vHPC suggesting that hippocampal protein degradation occurs very early in the consolidation process.

We next measured activity of the three major types of proteolytic activity of the $20 \mathrm{~S}$ proteasome. We found a statistically significant main effect for time on changes in chymotrypsin-like $\left(F_{(5,45)}\right.$ $=3.59, P<0.01)$, peptidylglutamyl $\left(F_{(5,45)}=5.60, P<0.001\right)$, and trypsin-like $\left(F_{(5,46)}=4.12, P<0.01\right)$ activity within the dHPC. Comparing each time point to the No Exposure controls, we found that dHPC chymotrypsin-like (Fig. 3D), peptidylglutamyl (Fig. 3E), and trypsinlike (Fig. 3F) activity all significantly increased immediately following context exposure $(P<0.05, P<0.001, P<0.01$, respectively) and returned to baseline levels by $30 \mathrm{~min}$. Similarly, we found statistically significant main effects for time after context exposure on chymotrypsin-like $\left(F_{(5,45)}=3.46, P<0.05\right)$, peptidylglutamyl $\left(F_{(5,46)}=4.79, P<0.01\right)$, and trypsin-like $\left(F_{(5,46)}=8.48, P<0.001\right)$ activity within the vHPC. Chymotrypsin-like activity significantly increased immediately following context exposure (Fig. 3G) compared to No Exposure controls $(P<0.05)$ and returned to baseline by 30-min. Chymotrypsin appeared to increase again at 90 and $120 \mathrm{~min}$; however, these differences were not statistically significant. Peptidylglutamyl activity was significantly elevated compared to No Exposure (Fig. $3 \mathrm{H}$ ) controls 90 min following context exposure $(P<0.05)$. Trypsin-like activity significantly increased relative to No Exposure controls immediately following context exposure $(P<0.01)$ and returned to 

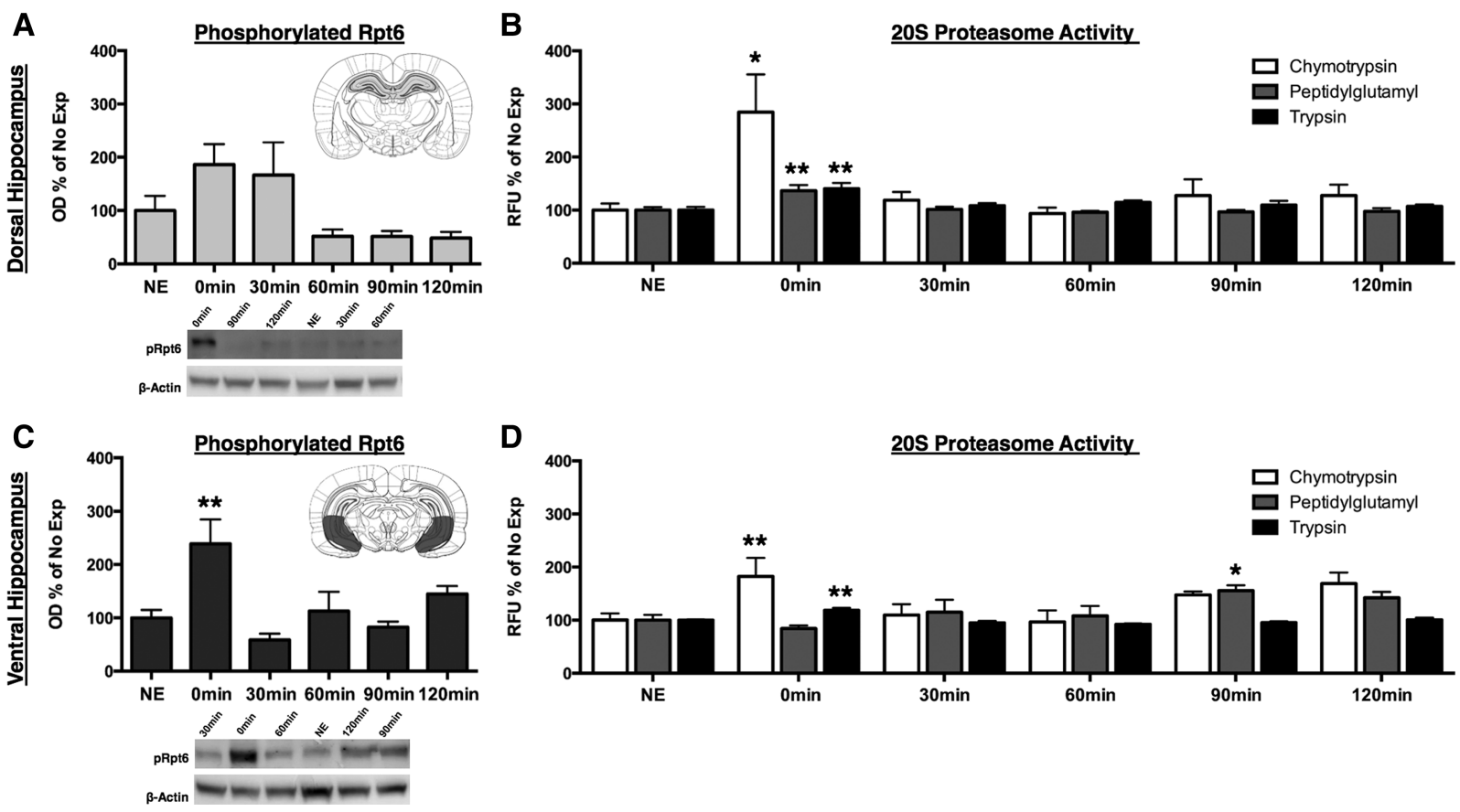

Figure 3. Proteolytic activity in the $\mathrm{dHPC}$ increases immediately and quickly returns to baseline while the vHPC exhibits a biphasic pattern of proteolytic following context exposure. Rats were given $5 \mathrm{~min}$ of context exposure, and dHPC and vHPC tissue were collected 0, 30, 60, 90, or 120 min later for Western blotting and in vitro proteasome activity assay. (A) Phosphorylation of Rpt6 normalized to $\beta$-actin and expressed as a percentage of the No Exposure (NE) control group. The inset is a representative section of dissected dHPC (light gray) tissue. Phosphorylated Rpt6 marginally increased at 0 and $30 \mathrm{~min}$ following context exposure and returned to baseline levels by $60 \mathrm{~min}$. (B) Raw fluorescent units (RFU) for the in vitro $20 \mathrm{~S}$ proteasome assay for dHPC chymotrypsin, peptidylglutamyl, and trypsin activities expressed as a percentage of the NE control. Chymotrypsin, peptidylglutamyl, and trypsin activities significantly increased immediately following context exposure and returned to baseline by 30 min. (C) Phosphorylation of Rpt6 normalized to $\beta$-actin and expressed as a percentage of the No Exposure (NE) control group. The inset is a representative section of dissected vHPC (dark gray) tissue. Phosphorylated Rpt6 significantly increased immediately and following context exposure and returned to baseline by 30 min. $(D)$ Raw fluorescent units (RFU) for the in vitro 20 S proteasome assay for vHPC chymotrypsin, peptidylglutamyl, and trypsin activities expressed as a percentage of the NE control. Chymotrypsin and trypsin activities significantly increased immediately following context exposure and returned to baseline by 30 min. Peptidylglutamyl activity significantly increased 90 min following context exposure and returned to baseline by $120 \mathrm{~min} .\left(^{*}\right) P<0.05,\left({ }^{* *}\right) P<0.01$.

baseline by $30 \mathrm{~min}$. Taken together, these data suggest that activity-dependent protein degradation is involved early in the consolidation process following context exposure. Further, these data suggest that while protein degradation occurs in both the dorsal and ventral hippocampus following context exposure, the two structures undergo distinct patterns of proteolytic activity during the consolidation of a context representation.

\section{Phosphorylated ERK in the dHPC increases immediately while pERK activity increases $2 \mathrm{~h}$ following context in the vHPC}

Finally, we wanted to further investigate the time-course of dHPC and vHPC involvement in the consolidation of contextual cues by measuring another plasticity marker, phosphorylation of ERK/ MAPK (pERK). We chose to measure pERK as a marker of plasticity based on a number of studies demonstrating the up-regulation of pERK within the hippocampus following long-term potentiation (English and Sweatt 1996, 1997), context fear conditioning (Chwang et al. 2006), as well as within the amygdala following auditory fear conditioning (Schafe et al. 1999) and auditory fear extinction (Parsons et al. 2010; Kwapis et al. 2014). Therefore, we used Western blots to measure changes in pERK within both the dHPC and vHPC following context exposure.

We found a significant main effect of time following context exposure on pERK activity in the dHPC $\left(F_{(5,46)}=7.92, P<0.001\right)$. Similar to proteolytic activity, pERK significantly increased imme- diately following context exposure $(P<0.01)$ relative to No Exposure controls and returned to baseline by 30-min (Fig. 4A). Additionally, we found a statistically significant main effect of time following context exposure on pERK activity within the $\operatorname{vHPC}\left(F_{(5,46)}=5.27, P<0.001\right)$ (Fig. $\left.4 \mathrm{~B}\right)$. In contrast to pERK activity in the dHPC, vHPC pERK activity significantly increased relative to No Exposure controls $120 \mathrm{~min}$ following context exposure $(P<0.05)$. Taken together these data suggest that the dHPC and vHPC undergo plasticity following context exposure at different time points. The dHPC appears to undergo synaptic plasticity immediately following context exposure, whereas synaptic plasticity within the vHPC occurs at a later time point.

\section{Discussion}

These data support a critical role of hippocampal protein degradation in the formation of memory for a novel environment independent of footshock. Blocking protein synthesis or protein degradation in both the dorsal and ventral hippocampus immediately following context exposure significantly impaired the memory for that context when assessed with the CPFE procedure. Further, we reported a rapid increase in proteolysis in the dHPC following context exposure that quickly returned to baseline levels. Proteolytic activity within the vHPC exhibited a biphasic activity pattern as we found immediate increases in phosphorylated Rpt6, chymotrypsin- and trypsin-like activity while peptidylglutamyl peptidase activity increased $90 \mathrm{~min}$ following context 
A
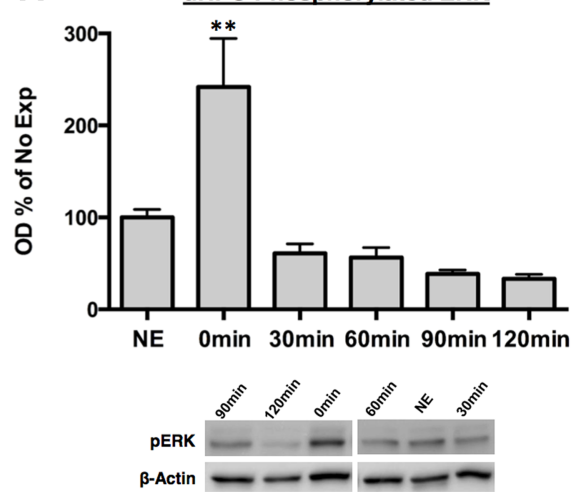

B
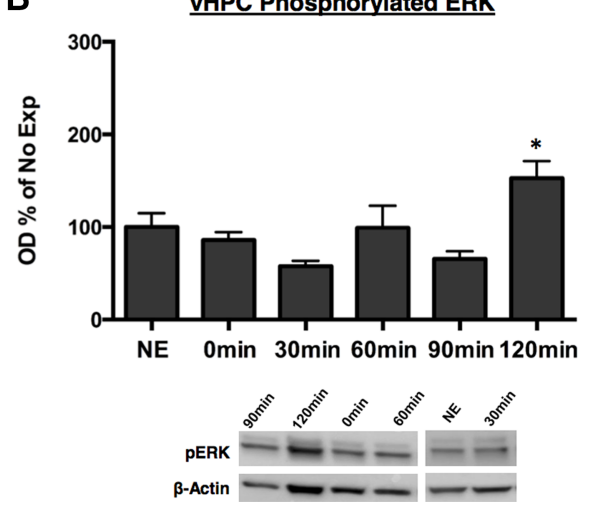

Figure 4. Phosphorylated ERK activity increases immediately following context exposure in the dHPC while increasing 120 min following context in the VHPC. Rats were given 5 min of context exposure and $\mathrm{dHPC}$ and vHPC tissue were collected $0,30,60,90$, or 120 min later for Western blotting. Phosphorylation of ERK normalized to $\beta$-actin and expressed as a percentage of the No Exposure (NE) control group. (A) Phosphorylated ERK activity significantly increased immediately following context exposure and returned to baseline levels by $30 \mathrm{~min}$. (B) Phosphorylated ERK activity significantly increased 120 min following context exposure. $\left(^{*}\right) P<0.05,\left(^{* *}\right) P<0.01$.

exposure. We also found that pERK, a kinase linked to synaptic plasticity in prior studies, increased immediately following context exposure in the dHPC while increasing $2 \mathrm{~h}$ following context exposure in the vHPC. Collectively, our results demonstrate that both de novo protein synthesis and UPS-mediated protein degradation are required in the hippocampus for the consolidation of a context memory.

Protein degradation during the formation of stable long-term memories is becoming more accepted as a critical regulator of synaptic plasticity. A number of studies have reported that activity-dependent protein degradation within the hippocampus, amygdala, and prefrontal cortex is critical for the formation and retrieval of long-term fear memories (Lee et al. 2008; Jarome et al. 2011, 2013; Reis et al. 2013). However, few studies have investigated the role of activity-dependent protein degradation in hippocampus-dependent spatial memory formation. Artinian et al. (2008) reported that protein degradation in the dHPC is required for the consolidation of an allocentric spatial memory using a water maze task. Similarly, Figueiredo et al. (2015) found that hippocampal protein degradation is required to form a long-term object recognition memory. The current study provides additional support for activity-dependent protein degradation as a critical step in the consolidation of spatial memory and is the first to demonstrate that UPS-mediated protein degradation, along with protein synthesis, is required in both the dorsal and ventral hippocampus for consolidating a nonaversive context memory.

The hippocampus has been extensively studied for its role in learning and memory, with the majority of research focusing on the dHPC. However, the vHPC has received increasingly more attention as recent evidence suggests a functional distinction between the dorsal and ventral portions of the hippocampus (Moser and Moser 1998; Dong et al. 2009; Fanselow and Dong 2010). A number of studies have provided evidence suggesting that the dHPC is primarily responsible for processing and storing spatial and contextual learning, whereas the vHPC plays a greater role in fear and anxiety processing (Jung et al. 1994; Moser et al. 1995; Kjelstrup et al. 2002; Maren and Holt 2004; Rogers and Kesner 2006; Hunsaker and Kesner 2008; Czerniawski et al. 2009). However, there have been some conflicting reports suggesting that the vHPC plays a role in spatial memory as well. For instance, Ferbinteanu et al. (2003) used a match-to-position version of the Morris water maze and found that both dorsal and text preexposure and immediate shock delivery and discovered an immediate shock deficit 2 min following context preexposure. This deficit persisted for up to $6 \mathrm{~h}$ following the context preexposure session. They proposed that the inability to exhibit the context memory is the result of a discontinuity between two separate processes that support memory: (1) very fast synaptic processes that decay rapidly and (2) slower synaptic changes that require more time to complete and decay at a much slower rate (Rudy 2005). Our data partially support this hypothesis and provide a potential synaptic mechanism for their observed retrieval deficit. Learning-induced hippocampal proteolytic activity is increased immediately following context exposure, suggesting that synapses in the dHPC and vHPC destabilize early in the consolidation process. The immediate post-exposure increase in hippocampal proteolytic activity parallels the time course of the memory impairment Rudy and Wright-Hardesty (2005) reported. Therefore, it is possible that UPS-mediated protein degradation may represent the first memory processes described by Rudy and Wright-Hardesty (2005). Following synaptic destabilization, the memory becomes temporarily unavailable until completion of the second memory process, de novo protein synthesis and restabilization of postsynaptic densities.

The idea that protein degradation corresponds to the first memory process proposed by Rudy and Wright-Hardesty (2005) would suggest that protein degradation precedes protein synthesis following a learning event and potentially regulates synthesis of new proteins, as proposed by Jarome and Helmstetter (2014). Supporting this idea, previous work indicates that learninginduced activity of protein degradation is related to increased polyubiquitination of the RNA-induced silencing complex factor MOV10 (Jarome et al. 2011), which when degraded, results in increased protein synthesis at the synapse (Banerjee et al. 2009). Further, simultaneous blockade of protein degradation and synthesis in the amygdala and dHPC following context and discrete-cued fear memory retrieval prevented the impairments typically caused by protein synthesis inhibition (Lee et al. 2008; Jarome et al. 2011). This suggests that UPS-mediated proteolysis regulates protein synthesis in addition to synaptic destabilization. However, it remains unclear exactly how protein degradation regulates de novo protein synthesis during memory consolidation. One potential link between proteolytic activity and protein synthesis is NMDA receptor (NMDAR)-dependent calcium/calmodulin-dependent protein kinase II (CaMKII). Recent evidence suggests that 
NDMAR-dependent increases in calcium and CaMKII signaling regulate phosphorylation and activity of the proteasome and blocking CamKII signaling prevents UPS-induced destabilization and subsequently impairs memory formation and reconsolidation processes (Jarome et al. 2013, 2016). In addition to regulating the UPS, NMDAR-dependent CaMKII signaling has been shown to trigger ERK phosphorylation, which regulates transcription factor activity and protein synthesis (Chwang et al. 2006; Wayman et al. 2008; El Gaamouch et al. 2012). Future investigations into the interaction between synaptic protein degradation and protein synthesis should focus on whether CaMKII directly regulates both processes either through regulating UPS activity and ERK signaling directly or through other potential "downstream" mechanisms by which synaptic destabilization controls subsequent de novo synthesis and restabilization of active synapses.

The current study provides strong evidence that the consolidation of a nonaversive context memory requires UPS-mediated protein degradation in both the dHPC and vHPC. We found that hippocampal proteolytic activity rapidly increased following context exposure and that blocking this activity significantly impaired memory for the context. These data complement the growing body of literature indicating that along with protein synthesis, activitydependent protein degradation plays a critical role in synaptic plasticity and memory consolidation. We also provide evidence that while both the AHPC and vHPC are involved in the consolidation of a context memory, the two structures undergo temporally distinct patterns of proteolytic activity following context exposure. Future research aimed at investigating the functional difference between the dHPC and vHPC during memory consolidation can help elucidate their individual roles in forming a unitary memory.

\section{Materials and Methods}

\section{Subjects}

We used 158 naïve male Long-Evans rats (300-400 g; Harlan, WI) housed individually in shoebox cages with free access to food and water in a room maintained on a 14:10 light-dark cycle. All experiments took place during the light portion of the cycle. Spring-Fill Crinkle Cut Kraft paper (Quality Packaging) paper bedding was provided as environmental enrichment. All procedures were carried out in a facility accredited by the Association for Assessment and Accreditation and Laboratory Animal Care and approved by the University of Wisconsin-Milwaukee Institutional Animal Care and Use Committee and conducted within the ethical guidelines of the National Institutes of Health.

\section{Surgical procedures}

Animals were anesthetized with isoflurane in 100\% oxygen (induction occurred with $4 \%$ isoflurane and maintained with $2 \%$ ). Rats were mounted in a stereotaxic apparatus (Kopf Instruments). Stainless steel 26-gauge guide cannulae (Plastics One, Inc.) were bilaterally inserted through the skull above CA1 region of either the dHPC or vHPC, and were anchored to the skull with two stainless steel screws and dental acrylic. Cannulae were positioned using the following coordinates with respect to bregma: $-3.5 \mathrm{~mm} \mathrm{~A} / \mathrm{P}, \pm 2.4$ $\mathrm{mm} \mathrm{M} / \mathrm{L},-2.5 \mathrm{~mm} \mathrm{D} / \mathrm{V}$ for CA1 region of the dorsal hippocampus; $-5.6 \mathrm{~mm} \mathrm{~A} / \mathrm{P}, \pm 5.5 \mathrm{~mm} \mathrm{M} / \mathrm{L}, 7.0 \mathrm{~mm} \mathrm{D} / \mathrm{V}$ for CA1 region of the ventral hippocampus. Dummy cannulae (33-gauge) were screwed into the guide cannulae to prevent occlusion.

\section{Drug preparation and infusion procedure}

Subjects were given 5-7 d to recover from surgery prior to behavioral procedures. Rats received $3 \mathrm{~d}$ of transport handling and were acclimated to the injection procedure. This consisted of carting animals into a room adjacent to the conditioning room and gently restraining them in a towel. The animals were habituated to the sound of the infusion pumps that would be used for intrace- rebral injections. No injections were delivered during the acclimation period. On the day of context exposure, rats received microinfusions of the protein synthesis inhibitor anisomycin (ANI) $(125 \mu \mathrm{g} / \mu \mathrm{L})$, the UPS inhibitor clasto-lactacystin- $\beta$-lactone ( $\beta \mathrm{Lac})(32 \mathrm{ng} / \mu \mathrm{L})$, or vehicle $(2 \% \mathrm{DMSO})$ into either the dHPC or vHPC. This dose of $\beta \mathrm{Lac}(32 \mathrm{ng} / \mu \mathrm{g}$ ) has been used in previous studies to successfully inhibit UPS activity and subsequently impair memory (Lee et al. 2008; Jarome et al. 2011, 2013; Ren et al. 2013; Reis et al. 2013). ANI and $\beta$ Lac were dissolved in $2 \%$ DMSO in $\mathrm{HCl}$, diluted in double-distilled water and brought to $\mathrm{pH} \sim 7.4$ with $\mathrm{NaOH}$. The injections $(0.5 \mu \mathrm{L} /$ side $)$ were delivered at a rate of $0.5 \mu \mathrm{L} / \mathrm{min}$ through 33-gauge gauge injection cannulae attached to a $1 \mu \mathrm{L}$ Hamilton syringe operated by a micro-infusion pump (Harvard Apparatus). Injectors were left in place for an additional $90 \mathrm{sec}$ following the injection to allow time for the drug to diffuse away from the injector tip. All injections occurred immediately following context exposure. Animals were returned to their home cages in the colony following drug injection.

\section{Behavioral procedures and apparatus}

Context preexposure occurred in one of two distinct contexts. The training context (Training) contains a set of four Plexiglas conditioning chambers $(21 \times 28 \times 21 \mathrm{~cm}$; stainless steel grid floors), each housed in a sound attenuating box illuminated with a white incandescent house light $(7.5 \mathrm{~mW})$. Context A was cleaned with $5 \%$ ammonium hydroxide and a ventilation fan provided background noise. The control context (Control) contains a set of four Plexiglas conditioning chambers $(20.5 \times 26.5 \times 21)$ housed in sound attenuating chambers with ventilation fans. These chambers are housed in a different room and contain course plastic flooring, illumination by an infrared houselight and are washed with $5 \%$ acetic acid.

In Experiment 1, all animals received $3 \mathrm{~d}$ of handling and habituation to infusion procedures. On the day of context preexposure, rats were placed into either the training context or control context for a 5-min preexposure session. Following the 5-min exposure, rats were removed and immediately infused with ANI, $\beta$ Lac, or vehicle into either the dHPC or vHPC. Rats were returned to the colony following drug administration. Twenty-four hours following context preexposure, all animals were carted into the training context and placed into the conditioning chamber, where rats received immediate shock delivery consisting of 5 (1-sec, $1 \mathrm{~mA}$ ) footshocks separated by a 1-sec ITI. The first footshock was delivered $1 \mathrm{sec}$ after the chamber door was closed. Rats were removed immediately upon shock cessation and returned to their homecages. Contextual fear was assessed $24 \mathrm{~h}$ following context conditioning by returning the rats to the training context for $5 \mathrm{~min}$. The percent time that animals spent freezing during the entire 5 -min period was used as the measure of conditioned fear. Experiment 1 consisted of 12 groups that received intra-dHPC injections (Control ANI, $n=9$; Control $\beta$ Lac, $n=6$; Control Vehicle, $n=6$; Training ANI, $n=10$; Training $\beta$ Lac, $n=6$; Training Vehicle, $n=6$ ) or intra-vHPC injections (Control ANI, $n=10$; Control $\beta$ Lac, $n=11$; Control Vehicle, $n=10$; Training ANI, $n=11$; Training $\beta$ Lac, $n=11$; Training Vehicle, $n=10$ ).

In Experiment 2, all animals were handled for $2 \mathrm{~min}$ for three consecutive days prior to context exposure. On the day of context exposure, animals were transported to the conditioning room and placed into Context A for $5 \mathrm{~min}$. Animals were returned to their homecages following context exposure and sacrificed $30 \mathrm{~min}(n$ $=7), 60 \mathrm{~min}(n=7), 90 \mathrm{~min}(n=8)$, or $120 \mathrm{~min}(n=8)$ following context exposure. One group of animals was sacrificed immediately following context exposure $(n=12)$. An additional group $(n=10)$ received the same treatment of transport and handling, but was not exposed to the context (NE) to assess baseline proteolytic activity.

\section{Synaptosomal membrane preparation}

Animals were sacrificed at the various time points described above with an overdose of isoflurane. Brains were rapidly removed and flash frozen on dry ice. The dHPC and vHPC were dissected out 
by blocking the brain in a rat brain matrix (Harvard Apparatus) incubated on dry ice. Synaptosomal membrane fractions were obtained using methods previously described by Jarome et al. (2011) with minor alterations. Tissue samples were homogenized in TEVP with $320 \mathrm{mM}$ Sucrose and centrifuged at $1000 \mathrm{~g}$ for 10 $\min$ at $4^{\circ} \mathrm{C}$. The supernatant was collected and spun at $10,000 \mathrm{~g}$ for $10 \mathrm{~min}$ at $4^{\circ} \mathrm{C}$. The resulting pellet, containing the synaptosomal fraction, was resuspended in Lysis buffer $(50 \mathrm{mM}$ Tris$\mathrm{HCl}, 6 \mathrm{mM}$ sodium deoxycholate, $150 \mathrm{mM} \mathrm{NaCl}, 1 \mathrm{mM} \mathrm{NaF}, 2$ Roche tablets, $0.1 \%$ SDS, $1 \mathrm{mM}$ sodium orthovanadate) and measured using a Bradford protein assay (BioRad).

\section{5 proteasome activity assay}

Proteasome assays were performed as previously described with minor modifications (Jarome et al. 2013). Samples (10 $\mu \mathrm{g})$ were diluted in $\mathrm{DDH}_{2} \mathrm{O}$ and mixed with reaction buffer (250 mM HEPES, $\mathrm{pH}$ 7.5, 5 mM EDTA, 0.5\% NP-40, 0.01\% SDS, 20 mM ATP). Fluorogenic peptides LLVY-AMC (Millipore) and Bz-VGR-AMC, z-LLeAMC (Enzo Life Sciences) were mixed into the reaction to assess chymotrypsin-, trypsin-, and peptidylglutamyl-like activities of the $26 \mathrm{~S}$ proteasome. Reactions were incubated at $37^{\circ} \mathrm{C}$ for $2 \mathrm{~h}$ and fluorescence was monitored in a monochromatic plate reader (Synergy H1; Biotek) at 360 (excitation)/460 (emission). Proteinfree blanks were used to assess auto-hydrolysis of the substrates and an AMC standard curve was produced following the manufacturer's instructions.

\section{Western blotting}

Synaptosomal membrane samples $(10 \mu \mathrm{g})$ were loaded on $7.5 \%$ TGX gels, subjected to SDS-PAGE and transferred to PVDF membranes using a Turbo Transfer System (BioRad). Membranes were rinsed in ddH20 for $5 \mathrm{~min}$ and incubated in blocking buffer $(5 \%$ milk in TBS with $0.1 \%$ Tween-20) for $1 \mathrm{~h}$ at room temperature. Membranes were then washed in TBS/T wash buffer and incubated in primary antibody and 3\%BSA in TBS with $0.1 \%$ Tween-20 overnight at $4^{\circ} \mathrm{C}$. Following overnight incubation, membranes were washed and incubated in secondary antibody (1:20,000, anti-goat-rabbit; Santa Cruz) in blocking buffer for $1 \mathrm{~h}$ at room temperature. Following final wash, membranes were incubated in chemiluminescence substrate (SuperSignal West Dura, Thermo) for $5 \mathrm{~min}$. Images were developed and captured using G-Box Chemi XT-4 camera system (Syngene). Primary antibodies included a custom phospho-Rpt6-Serine 120 (pS120) rabbit polyclonal antibody generated commercially (ProSci) (described in Jarome et al. 2013), pERK (1:500, Cell Signaling), and $\beta$-actin (1:1000, Cell Signaling).

\section{Analyses}

For Experiment 1, freezing, defined as the absence of all movement minus the movement associated with breathing, was used as the measure of conditional fear during the test session. Freezing was measured automatically in real-time using FreezeScan detection software (Celver Sys, Inc.). Freezing responses during contextual fear testing were analyzed using a 2 (Context) $\times 3$ (Drug) factorial analysis of variance (ANOVA). Statistically significant main effects or interactions were followed up with Tukey post hoc comparisons. For the quantitative protein assays, the mean optical density for each sample was analyzed with GeneSYS analysis software (Syngene). The optical density of phospho-Rpt6 and pERK was normalized to the loading control, $\beta$-actin, and then expressed as a percentage of the No Exposure control group. For proteasome activity assays, the raw fluorescence score for each sample was standardized to the generated AMC standard curve for that plate and then expressed as a percentage of the No Exposure control group. The normalized Western blot and proteasome assay data were then analyzed using one-way ANOVAs and followed up with Dunnett's post hoc test comparing each time point to the No Exposure control group.

\section{Histology}

At the end of Experiment 1, animals were deeply anesthetized with isoflurane, transcardially perfused with $0.9 \%$ saline followed by $10 \%$ buffered formalin. Brains were removed and post-fixed in $10 \%$ formalin for $24 \mathrm{~h}$ before being transferred to $30 \%$ sucrose/formalin. The brains were then frozen, sectioned into coronal sections $40 \mu \mathrm{m}$ thick and mounted on glass slides for cresyl violet staining.

\section{Acknowledgments}

This work was supported by National Institutes of Health (NIH) grants R01-MH069558 (National Institute of Mental Health) and R21-AG053854 (National Institute on Aging) (F.J.H.).

\section{References}

Alberini CM. 2009. Transcription factors in long-term memory and synaptic plasticity. Physiol Rev 89: 121-145.

Artinian J, McGauran AMT, De Jaeger X, Mouledous L, Frances B, Roullet P. 2008. Protein degradation, as with protein synthesis, is required during not only long-term spatial memory consolidation but also reconsolidation. Eur J Neurosci 27: 3009-3019.

Bailey DJ, Kim JJ, Sun W, Thompson RF, Helmstetter FJ. 1999. Acquisition of fear conditioning in rats requires the synthesis of mRNA in the amygdala. Behav Neurosci 113: 276-282.

Banerjee S, Neveu P, Kosik KS. 2009. A coordinated local translational control point at the synapse involving relief from silencing and MOV10 degradation. Neuron 64: 871-884.

Barrientos RM, O'Reilly RC, Rudy JW. 2002. Memory for context is impaired by injecting anisomycin into dorsal hippocampus following context exploration. Behav Brain Res 134: 299-306.

Chwang WB, O'Riordan KJ, Levenson JM, Sweatt JD. 2006. ERK/MAPK regulates hippocampal histone phosphorylation following contextual fear conditioning. Learn Mem 13: 322-328.

Czerniawski J, Yoon T, Otto T. 2009. Dissociating space and trace in dorsal and ventral hippocampus. Hippocampus 19: 20-32.

Dong HW, Swanson LW, Chen L, Fanselow MS, Toga AW. 2009. Genomic-anatomic evidence for distinct functional domains in hippocampal field CA1. Proc Natl Acad Sci 106: 11794-11799.

El Gaamouch FE, Buisson A, Moustie O, Lemieux M, Labrecque S, Bontempi B, De Koninck P, Nicole O. 2012. Interaction between $\alpha$ CamKII and GluN2B controls ERK-dependent plasticity. J Neurosci 32: 10767-10779.

English JD, Sweatt JD. 1996. Activation of p42 mitogen-activated protein kinase in hippocampal long term potentiation. J Biol Chem 271: 24329-24332.

English JD, Sweatt JD. 1997. A requirement for the mitogen-activated protein kinase cascade in hippocampal long term potentiation. J Biol Chem 272: 19103-19106.

Fanselow MS. 1990. Factors governing one-trial contextual conditioning. Anim Learn Behav 18: 264-270.

Fanselow MS, Dong HW. 2010. Are the dorsal and ventral hippocampus functionally distinct structures? Neuron 65: 7-19.

Ferbinteanu J, Ray C, McDonald RJ. 2003. Both dorsal and ventral hippocampus contribute to spatial learning in Long-Evans rats. Neurosci Lett 345: 131-135.

Figueiredo LS, Dornelles AS, Petry FS, Falavigna L, Dargél VA, Köbe LM, Aguzzoli C, Roesler R, Schröder N. 2015. Two waves of proteasome-dependent protein degradation in the hippocampus are required for recognition memory consolidation. Neurobiol Learn Mem 120: $1-6$.

Flexner JB, Flexner LB, Stellar E. 1963. Memory in mice as affected by intracerebral puromycin. Science 141: 57-59.

Freeman FM, Rose SP, Scholey AB. 1995. Two time windows of anisomycin-induced amnesia for passive avoidance training in the day-old chick. Neurobiol Learn Mem 63: 291-295.

Guzowski JF, McGaugh JL. 1997. Antisense oligodeoxynucleotide-mediated disruption of hippocampal cAMP response element binding protein levels impairs consolidation of memory for water maze training. Proc Natl Acad Sci 94: 2693-2698.

Hegde AN. 2010. The ubiquitin-proteasome pathway and synaptic plasticity. Learn Mem 17: 314-327.

Huff NC, Rudy JW. 2004. The amygdala modulates hippocampus-dependent context memory formation and stores cue-shock associations. Behav Neurosci 118: 53-62.

Hunsaker MR, Kesner RP. 2008. Dissociations across the dorsal-ventral axis of CA3 and CA1 for encoding and retrieval of contextual and auditory-cued fear. Neurobiol Learn Mem 89: 61-69. 
Jarome TJ, Helmstetter FJ. 2013. The ubiquitin-proteasome system as a critical regulator of synaptic plasticity and long-term memory formation. Neurobiol Learn Mem 105: 107-116.

Jarome TJ, Helmstetter FJ. 2014. Protein degradation and protein synthesis in long-term memory formation. Front Mol Neurosci 7: 61.

Jarome TJ, Werner CT, Kwapis JL, Helmstetter FJ. 2011. Activity dependent protein degradation is critical for the formation and stability of fear memory in the amygdala. PLOS ONE 6: e24349.

Jarome TJ, Kwapis JL, Ruenzel WL, Helmstetter FJ. 2013. CaMKII, but not protein kinase A, regulates Rpt6 phosphorylation and proteasome activity during the formation of long-term memories. Front Behav Neurosci 7: 115.

Jarome TJ, Ferrara NC, Kwapis JL, Helmstetter FJ. 2016. CaMKII regulates proteasome phosphorylation and activity and promotes memory destabilization following retrieval. Neurobiol Learn Mem 128: 103-109.

Jung MW, Wiener SI, McNaughton BL. 1994. Comparison of spatial firing characteristics of units in dorsal and ventral hippocampus of the rat. $J$ Neurosci 14: 7347-7356.

Kida S, Josselyn SA, Peña de Ortiz S, Kogan JH, Chevere I, Masushige S, Silva AJ. 2002. CREB required for the stability of new and reactivated fear memories. Nat Neurosci 5: 348-355.

Kinney JW, Sanchez-Alavez M, Barr AM, Criado JR, Crawley JN, Behrens MM, Henriksen SJ, Bartfai T. 2009. Impairment of memory consolidation by galanin correlates with in vivo inhibition of both LTP and CREB phosphorylation. Neurobiol Learn Mem 92: 429-438.

Kish-Trier E, Hill CP. 2013. Structural biology of the proteasome. Annu Rev Biophys 42: 29-49.

Kjelstrup KG, Tuvnes FA, Steffenach HA, Murison R, Moser EI, Moser MB. 2002. Reduced fear expression after lesions of the ventral hippocampus. Proc Natl Acad Sci 99: 10825-10830.

Kwapis JL, Jarome TJ, Lee JL, Gilmartin MR, Helmstetter FJ. 2014. Extinguishing trace fear engages the retrosplenial cortex rather than the amygdala. Neurobiol Learn Mem 113: 41-54.

Lee SH, Choi JH, Lee N, Lee HR, Kim JI, Yu NK, Choi SL, Lee SH, Kim H, Kaang BK. 2008. Synaptic protein degradation underlies destabilization of retrieved fear memory. Science 319: 1253-1256.

Lopez-Salon M, Alonso M, Vianna MR, Viola H, Mello e Souza T, Izquierdo I, Pasquini JM, Medina JH. 2001. The ubiquitin-proteasome cascade is required for mammalian long-term memory formation. Eur J Neurosci 14: $1820-1826$.

Maren S, Holt WG. 2004. Hippocampus and Pavlovian fear conditioning in rats: muscimol infusions into the ventral, but not dorsal, hippocampus impair the acquisition of conditional freezing to an auditory conditional stimulus. Behav Neurosci 118: 97-110.

Montarolo PG, Goelet P, Castellucci VF, Morgan J, Kandel ER, Schacher S. 1986. A critical period for macromolecular synthesis in long-term heterosynaptic facilitation in Aplysia. Science 234: 1249-1254.
Moser MB, Moser EI. 1998. Functional differentiation in the hippocampus. Hippocampus 8: 608-619.

Moser MB, Moser EI, Forrest E, Andersen P, Morris RG. 1995. Spatial learning with a minislab in the dorsal hippocampus. Proc Natl Acad Sci 92: 9697-9701.

Parsons RG, Gafford GM, Helmstetter FJ. 2010. Regulation of extinction-related plasticity by opioid receptors in the ventrolateral periaqueductal gray matter. Front Behav Neurosci 4: 44.

Reis DS, Jarome TJ, Helmstetter FJ. 2013. Memory formation for trace fear conditioning requires ubiquitin-proteasome mediated protein degradation in the prefrontal cortex. Front Behav Neurosci 7: 150 .

Ren ZY, Liu MM, Xue YX, Ding ZB, Xue LF, Zhai SD, Lu L. 2013. A critical role for protein degradation in the nucleus accumbens core in cocaine reward memory. Neuropsychopharmacology 38: 778-790.

Rogers JL, Kesner RP. 2006. Lesions of the dorsal hippocampus or parietal cortex differentially affect spatial information processing. Behav Neurosci 120: $852-860$.

Rudy JW. 2005. The temporal dynamics of retention of a context memory: something is missing. Learn Mem 12: 172-177.

Rudy JW, Matus-Amat P. 2005. The ventral hippocampus supports a memory representation of context and contextual fear conditioning: implications for a unitary function of the hippocampus. Behav Neurosci 119: $154-163$.

Rudy JW, O'Reilly RC. 1999. Contextual fear conditioning, conjunctive representations, pattern completion, and the hippocampus. Behav Neurosci 113: 867-880.

Rudy JW, Wright-Hardesty K. 2005. The temporal dynamics of retention of a context memory: something is missing. Learn Mem 12: 172-177.

Schafe GE, Nadel NV, Sullivan GM, Harris A, LeDoux JE. 1999. Memory consolidation for contextual and auditory fear conditioning is dependent on protein synthesis, PKA, and MAP kinase. Learn Mem 6: 97-110.

Wayman GA, Lee YS, Tokumitsu H, Silva AJ, Soderling TR. 2008. Calmodulin-kinases: modulators of neuronal development and plasticity. Neuron 59: 914-931.

Westbrook RF, Good AJ, Kiernan MJ. 1994. Effects of the interval between exposure to a novel environment and the occurrence of shock on the freezing responses of rats. QJ Exp Psychol B 47: 427-436.

Yeh SH, Lin CH, Gean PW. 2004. Acetylation of nuclear factor- $\kappa \mathrm{B}$ in rat amygdala improves long-term but not short-term retention of fear memory. Mol Pharmacol 65: 1286-1292.

Received February 28, 2017; accepted in revised form August 9, 2017. 


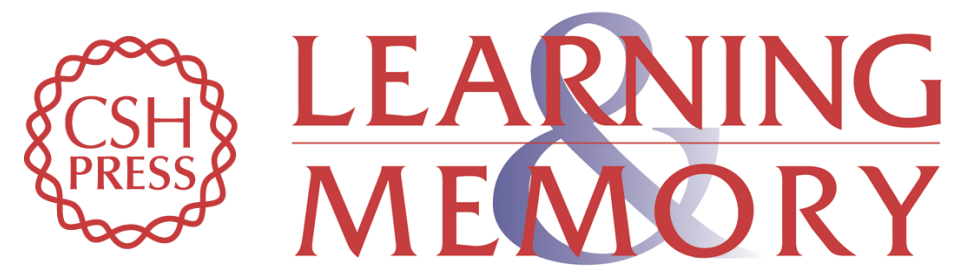

\section{Context memory formation requires activity-dependent protein degradation in the hippocampus}

Patrick K. Cullen, Nicole C. Ferrara, Shane E. Pullins, et al.

Learn. Mem. 2017, 24:

Access the most recent version at doi:10.1101/Im.045443.117

References This article cites 50 articles, 17 of which can be accessed free at: http://learnmem.cshlp.org/content/24/11/589.full.html\#ref-list-1

Creative This article is distributed exclusively by Cold Spring Harbor Laboratory Press for the Commons License first 12 months after the full-issue publication date (see

http://learnmem.cshlp.org/site/misc/terms.xhtml). After 12 months, it is available under a Creative Commons License (Attribution-NonCommercial 4.0 International), as described at http://creativecommons.org/licenses/by-nc/4.0/.

Email Alerting Receive free email alerts when new articles cite this article - sign up in the box at the Service top right corner of the article or click here. 